\title{
Visualization in endodontics
}

\section{James K. Bahcall}

Department of Endodontics Diplomate, American Board of Endodontics, Midwestern University College of Dental Medicine, Downers Grove, IL, USA

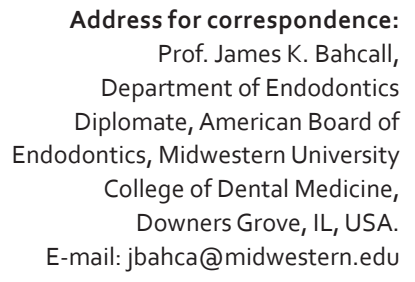

\section{ABSTRACT}

The field of endodontics has witnessed significant technological advances over the past decade. One area of advancement has been the evolution of endodontic visualization. As we begin to view conventional and surgical endodontic treatments as microsurgical procedures, we encounter the same demands for critical visualization as do areas within the field of medicine that perform microsurgery. This article will discuss the use of loupes, microscopes, endodscopes and orascopes in endodontic treatment.

Key words

Endodontic visualization, magnification, optics

\section{INTRODUCTION}

Visualization of surgical and conventional endodontic treatment has historically been limited to the two-dimensions of a dental radiograph that is representative of a three-dimensional biological system. Today, endodontic treatment is viewed as a microsurgical procedure. The basic finding upon which all microsurgery is based is the observation that the hand can perform remarkably intricate micromanipulations as long as the eye can see a magnified field and guide it properly. ${ }^{[1]}$ Magnification affects vision by increasing the size of an image on the retina which, in vision through a human eye, is quantified by the visual angle which this image subtends. This "visual image" is the basic parameter used to describe how big something appears to be and is expressed in units of degree or cycles/degree. ${ }^{[2]}$ The integration of optical magnification instruments such as loupes, microscopes, endoscopes and orascopes in to the endodontic treatment armamentarium, enables the endodontist to magnify a specified treatment field beyond that of the naked eye.

\begin{tabular}{|l|l|}
\hline \multicolumn{2}{|c|}{ Access this article online } \\
\hline Quick Response Code: & Website: \\
\hline & www.ejgd.org \\
\cline { 2 - 3 } & \\
\hline & DOI: \\
\hline
\end{tabular}

\section{OPTICAL DEFINITIONS}

\section{Working distance}

The distance measured from the dentist's eye to the treatment field being viewed.

\section{Depth of field}

The amount of distance between the nearest and the farthest objects that appear in acceptably sharp focus.

\section{Convergence angle}

The aligning of two oculars in order that they are pointing at the identical distance and angle to the object or treatment field.

\section{Field of view}

The area that is visible through optical magnification.

\section{Viewing angle}

The angular position of the optics that allow for a comfortable viewing position for the operator.

\section{LOUPES}

Dental loupes are the most common magnification system used in dentistry. All loupes use convergent lenses to form a magnified image. ${ }^{[3]}$ The simplest form of optical magnification is single lens loupes (i.e., jeweler's flip-down magnifiers). Single lenses have a fixed focal length and working distance. ${ }^{[4]}$ The advantages to these 
types of loupes are low cost and lightweight since they are made out of plastic. The disadvantage to single lens loupes is the poor image resolution as compared to multi-lens glass optics (telescopic loupes and microscopes). ${ }^{[5]}$ Since single lens loupes provide a set working distance, the dentist may find the ergonomics incorrect and may need to compensate by using poor body posture causing the possibility of neck and back strain while performing a procedure.

In order to overcome the disadvantages of single lens loupe optics, the use of multi-lens optic system is recommended. This type of glass multi-lens configuration is known as a Galilean optical system [Figure 1]. It provides a higher level of magnification, improved depth of field and working distance along with high optical resolution as compared to single plastic lens optics. ${ }^{[4]}$ Telescopic loupes use the Galilean optics. The ideal magnification with telescopic loupes is $\times 2.5$. This offers a good compromise between weight, optical performance and cost. Galilean lens systems cannot offer magnification much greater than $\times 2.5$ without incurring weight, size, and image resolution problems. ${ }^{[5]}$ Silber $^{[1]}$ recommends the use of $\times 2.5$ operating loupes because the magnification of loupes greater than $\times 2.5$ limits the depth of field and working distance during treatment. Any head movement of the operator while using loupes with magnification greater than $\times 2.5$ will cause a treatment field to come in and out of focus. This can be very distracting and irritating to the clinician. When the need for higher magnification is required (up to $\times 6$ ), prism optics are required. This optical system is based upon the Keplarian astronomical telescope which uses five lenses and two prisms. The advantages to this optical system are superior optical clarity and flatter view from edge to edge. However, the disadvantages are expense and added weight to loupes. ${ }^{[5]}$ As the magnification in loupes increases, the need for more illumination is required..$^{[6]}$ Loupe manufacturers have designed portable clip on light sources to accommodate this demand for increase light.

\section{MICROSCOPES}

Baumann ${ }^{[7]}$ was the first to report in the literature the use and benefits of the operating microscope for conventional endodontics. Since this time, the use of the surgical operating microscope (SOM) has evolved in the field of endodontics as an invaluable optical magnification instrument ${ }^{[8-10]}$ [Figure 2]. Today, this visual evolution in endodontics from using loupes and headlamps to the use of the microscope parallels a similar transition in various medical specialties, such as ophthalmology and neurosurgery. ${ }^{[1]}$ On January 1, 1998, the American Dental Association standards for advanced specialty education programs in endodontics were revised to include that formal microscope training must be given in surgical and non-surgical endodontic treatment. ${ }^{[1]}$

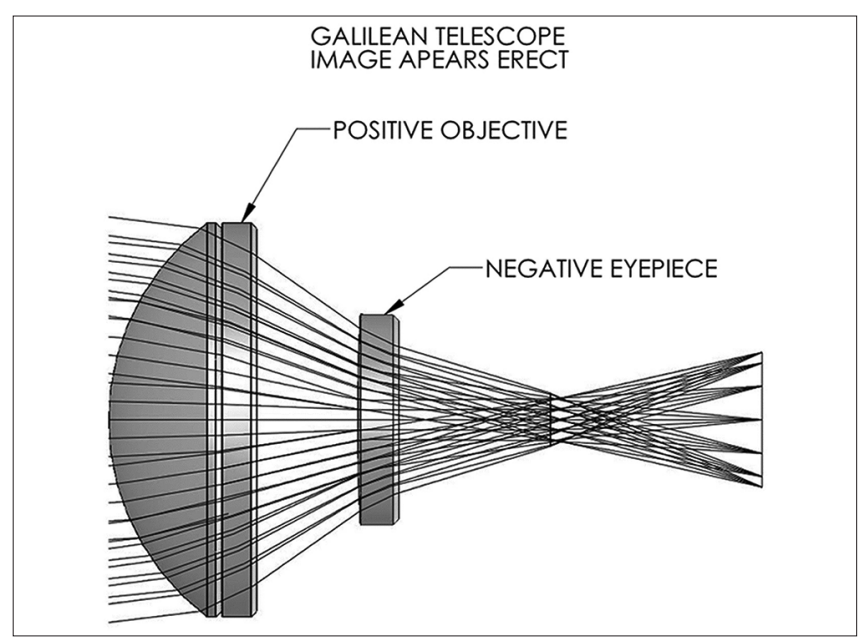

Figure 1: Diagram of Galilean optics (Illustration courtesy of Designs for Vision, Inc., Ronkonkoma, NY)

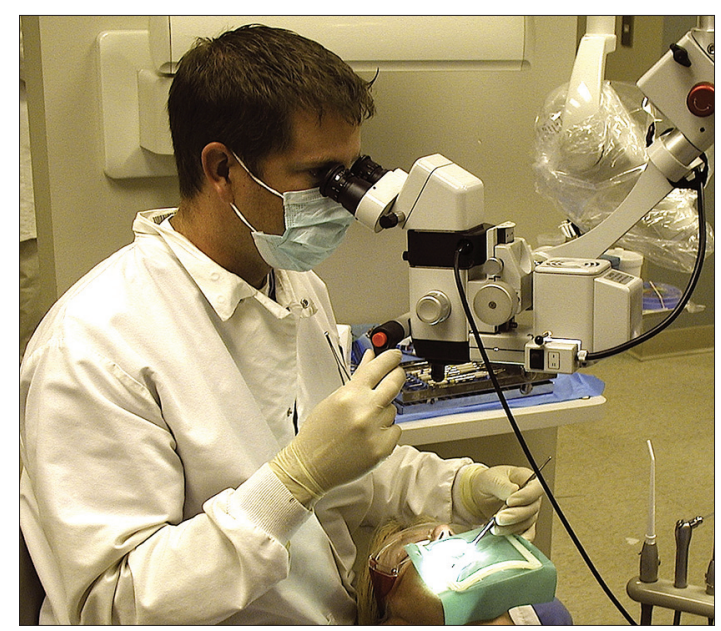

Figure 2: Clinical use of surgical operating microscope (Photo courtesy of JEDMED, St. Louis, MO)

The magnification needs in endodontic treatment usually range from $\times 3$ to $\times 30{ }^{[12]} \mathrm{A} S \mathrm{SOM}$ is able to accommodate these magnification requirements. Although loupes can have a magnification as high as $\times 6$, they are not able to provide the same depth of field at $\times 6$ magnification as compared to the microscope ${ }^{[1]}$ and the fiber optic light source of the SOM provides 2-3 times the light emitted from a surgical headlamp. ${ }^{[13]}$

Similar to loupes, the microscope uses the Galilean lens system. The magnification of the SOM is determined by the magnification power of the eyepiece, the focal length of the binoculars, the magnification changer factor and the focal length of the objective lens [Figure 3]. ${ }^{[12,14]}$ The eyepiece has adjustable diopter settings ranging from -5 to +5 . Diopter settings help the clinician to focus the lens of the eyes and adjust for refractive error, which is the degree to which a person needs to wear corrective eyeglasses. ${ }^{[12]}$

The benefits of using a SOM for optical magnification in conventional endodontic treatment are well documented 
in the literature. ${ }^{[15-19]}$ These clinical advantages of the microscope use in conventional endodontic treatment are increased visualization of the treatment field, enhanced visualization in locating canals, aiding in the removal of separated instruments, diagnosis of micro fractures, perforation repair and case documentation.

The advantages of using a SOM during surgical endodontic treatment are enhanced view of the surgical treatment field need for taking fewer radiographs during the surgical procedure and the ability to document the treatment. ${ }^{[20]}$

When viewing an endodontic treatment field through a microscope, the use of a standard dental mirror or micro-mirror is usually required in conjunction with the microscope to overcome the angulation difficulties of certain tooth positions in the mouth.

Saunders et al. ${ }^{[15]}$ states that the most common reasons for endodontists not using the SOM as often during treatment are positional difficulties, inconvenience and increase treatment time.

\section{ROD-LENS ENDOSCOPE}

The use of a rod-lens endoscope in endodontics was first reported in the literature in 1979. ${ }^{[21]}$ In 1996, the use of a rod-lens endoscope was documented in the literature for use as a magnification instrument for conventional and surgical endodontic procedures. ${ }^{[22,23]}$ The rod-lens endoscope [Figure 4] is made up of rods of glass work injunction with a camera, light source and a monitor [Figure 5]. The option of a digital recorder (either streaming video or still capture) can be added to the system for documentation of a procedure.

The rod-lens endoscope allows clinicians greater magnification than what can be achieved with loupes or a microscope with the optical resolution comparable to the microscope and loupes. Although the endoscope can be used as a visualization instrument for conventional endodontic treatment, it can be bulky and difficult to maintain a fixed field of vision as compared to a microscope. A fixed field of vision is defined as viewing a treatment field from one single angle and distance. ${ }^{[24]}$ The use of the endoscope is, therefore, recommended for visualization of surgical endodontic treatment. ${ }^{[22-27]}$ The visualization advantage in surgical endodontic treatment that the endoscope provides over the use of the microscope is the ability to view a surgical treatment field in a non-fixed field of vision. This is defined as the ability to view a treatment field at various angles and distances without losing depth of field and focus. ${ }^{[24]}$

The recommended rod-lens endoscope sizes for endodontic surgical application is a $2.7 \mathrm{~mm}$ lens

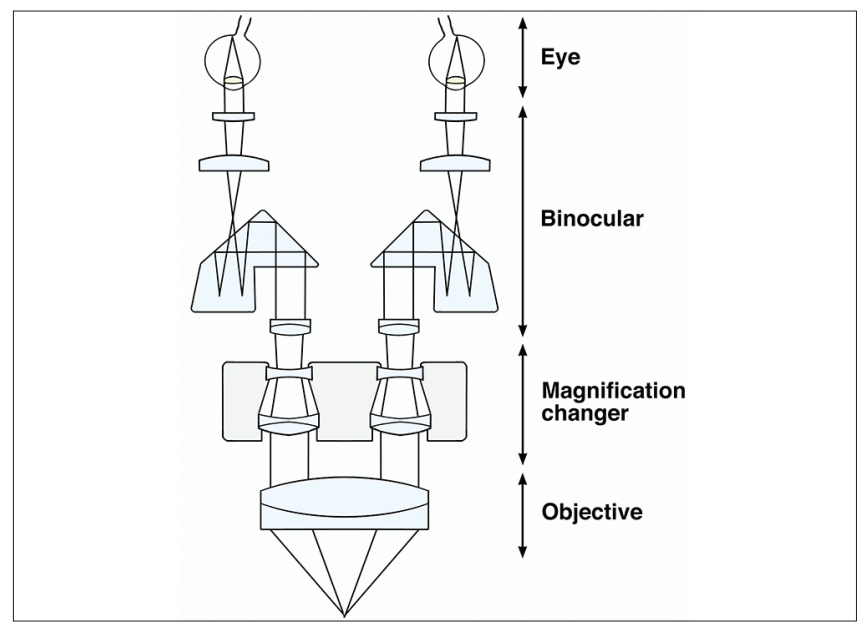

Figure 3: A schematic diagram of the surgical operating microscope. The eyepiece connected to binocular field glasses allows adequate focal length. The objective lens increases the magnification. The magnification changer adds to the flexibility of the microscope

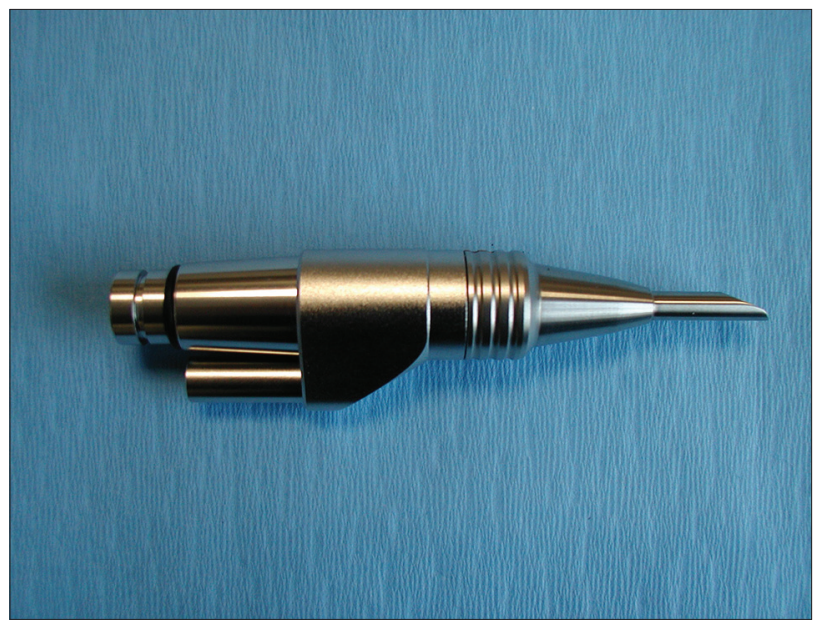

Figure 4: A rod-lens endoscope (JEDMED, St. Louis, MO)

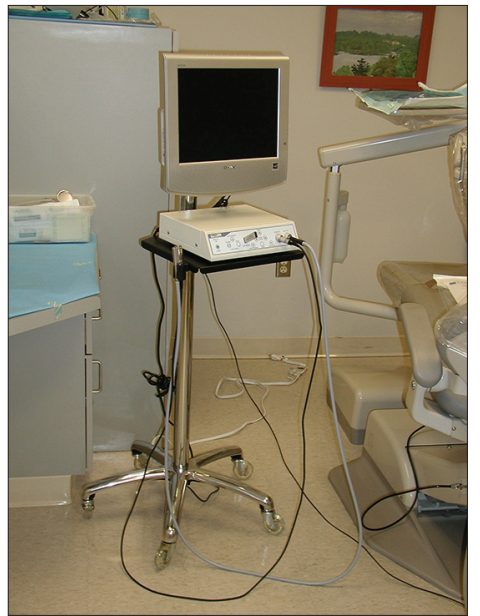

Figure 5: Endoscope visual system (JEDMED, St. Louis, MO)

diameter, $70^{\circ}$ angulation, $3 \mathrm{~cm}$ length rod-lens and a $4 \mathrm{~mm}$ lens diameter, $30^{\circ}$ angulation, and $4 \mathrm{~cm}$ length 
rod-lens. ${ }^{[24]}$ A pair of 2-2.5 $\times$ loupes should be used for visualization prior to the use of the endoscope..$^{[1,24]}$ Loupes aid the endodontist in surgical endodontic treatment to reflect gingival tissue, remove cortical and medullary bone, and isolate the root end. The clinician should hold the endoscope while the assistant retracts gingival tissue and suctions during surgical treatment. ${ }^{[2]}$

This helps in maintaining good eye-hand coordination for the operator during examination or treatment. The clinician and the assistant(s) view the magnified image from the monitor.

Hemostasis of the surgical field must be obtained before the endoscope is used because the scope cannot provide a discernible image when placed in blood. The warmth of the blood can also create condensation to occur on the lens. If this occurs, the use of suction and irrigation or an anti-fogging agent placed on the lens can be used to eliminate the fogging effect. The endoscope should be placed on bone around the crypt in order to stabilize scope. A protective metal sheath is placed over the endoscope prior to usage to add rigidity and allow the endoscope to be held in a stable position. It is not recommended to use the endoscope to also retract gingival tissue while viewing a surgical treatment field. This will not allow free movement of the scope by the operator to view a treatment field without having difficulty keeping the gingival tissue out of the line of sight.

\section{ORASCOPE}

An orascope is a fiber optic endoscope and like the rod-lens endoscope works injunction with a camera, light source and a monitor. Fiber optics are made of plastics, and therefore, are small, lightweight, and flexible. It is important to note that the image quality from fiber optic magnification has a direct correlation to the number of fibers and size of the lens used. The fiber optic endoscope is designed for intracanal visualization. ${ }^{[28]}$ The orascope has a $0.8 \mathrm{~mm}$ tip diameter, $0^{\circ}$ lens and the working portion is $15 \mathrm{~mm}$ in length [Figure 6]. The orascope is made up of 10,000 parallel visual fibers. Each visual fiber is between 3.7 microns and 5.0 microns in diameter. A ring of much larger light transmitting fibers surrounds the visual fibers for illumination of a treatment field [Figure 7].

Prior to the placement of the $0.8 \mathrm{~mm}$ fiber optic scope, it is recommended that $2-2.5 \times$ loupes or a SOM be used for conventional endodontic visualization to access the canal(s). A canal must be prepared to a minimum size of a \#90 file in the coronal $15 \mathrm{~mm}$ of the canal. If the canal is under instrumented, a wedging of the orascope may damage some of the fiber optic bundles within the scope. The proper canal enlargement also allows the full $15 \mathrm{~mm}$ of the scope to penetrate within the canal. The canal

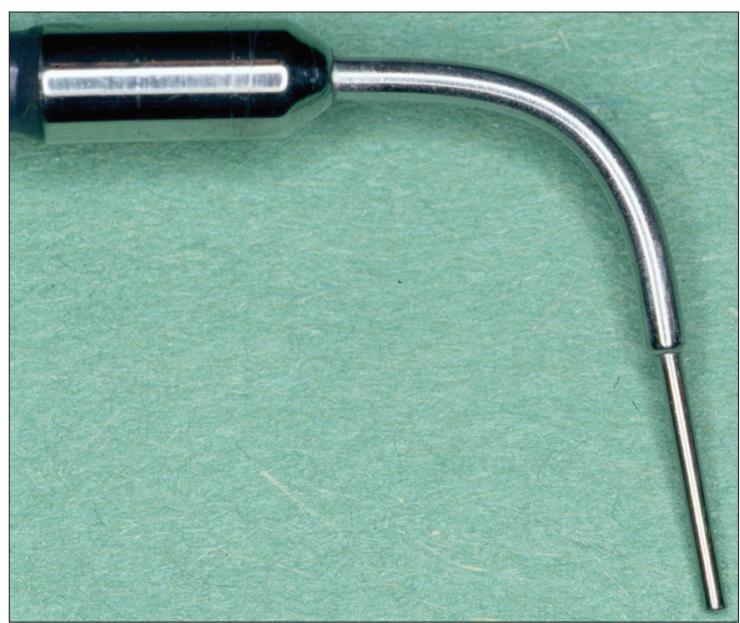

Figure 6: An orascope (JEDMED, St. Louis, MO)

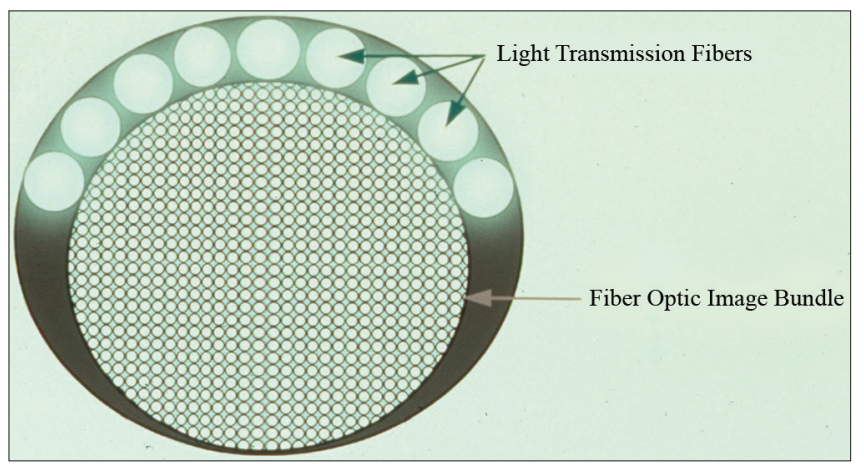

Figure 7: Cross-section of orascope probe showing the distribution of fiber optic image bundle and the light transmission fibers

must also be dried before the $0.8 \mathrm{~mm}$ fiber optic scope is placed. Although, the scope will see through sodium hypochlorite, this solution has a high light refractory index. This will cause greater amounts of light that will be reflected, thus, making it difficult to see details of the canal.

The focus and depth of field of an orascope is from $0 \mathrm{~mm}$ to $\infty$. This allows the orascope to provide imaging of the apical third of the root without actually having to be placed in this region of the canal.

Similar to the endoscope, the endodontist holds the orascope while viewing the image from the monitor. ${ }^{[28]}$ Temperature and humidity difference between the dental operatory and the canal can cause moisture to condense on the fiber optic lens, thus resulting in fogging. The use of a lens anti-fog solution can help eliminate this lens condensation build up.

\section{MICROSCOPE-ENDOSCOPE COMBINATION}

In conventional and surgical endodontic treatment, there are different visualization parameters for each type of treatment, when magnification beyond what is obtained 
from loupes is required. Although, both the microscope and rod-lens endoscope can be used for magnification for either type of endodontic treatment, the advantages for using a microscope for conventional endodontic treatment and a rod-lens endoscope for surgical visualization led to the development of a microscope coupler (JEDMED, Inc. St. Louis, MO) that enables the endodontists to combine both technologies [Figure 8]. The combination unit also allows for the use of the orascope and digital documentation.

\section{MAGNIFICATION VERSUS DIFFERENTIATION}

Magnification is defined as making an object or treatment field greater in size. Differentiation is defined as making something distinct or specialized. ${ }^{[29]}$ The need to differentiate a magnified treatment field in conventional endodontic therapy when looking for a fracture or in surgical endodontic therapy when trying to identify the periodontal ligament (PDL), an isthmus or marginal leakage around a previous root-end filling is important. Methylene blue, a nontoxic, biocompatible dye, is used in conjunction with endodontic visualization instruments to help differentiate a treatment field in order to aid the endodontist in identifying etiology ${ }^{[30]}$ [Figure 9].

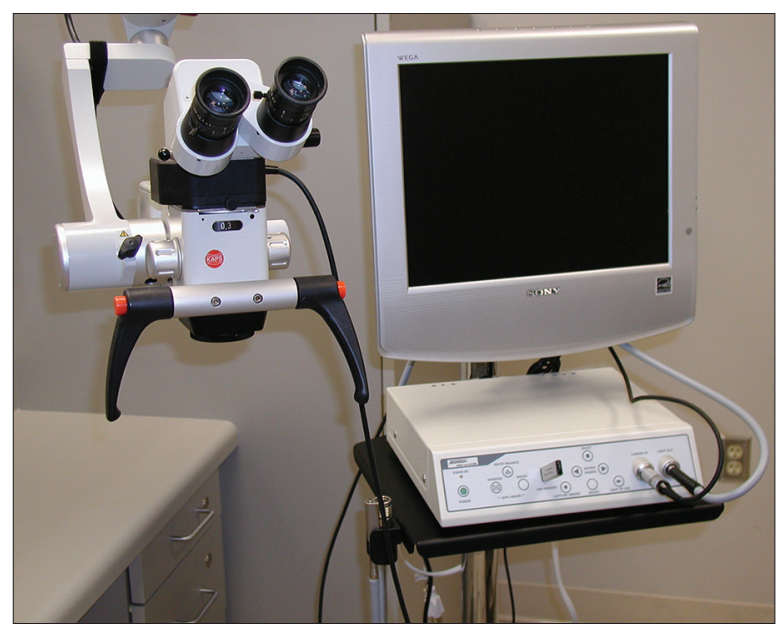

Figure 8: Combination microscope-endoscope visualization system (JEDMED, St. Louis, MO)

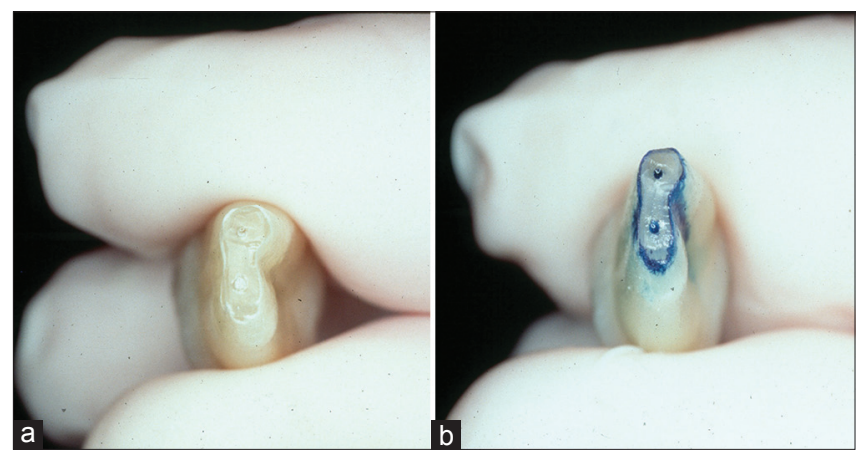

Figure 9: (a) Magnification of a root end without differentiation, (b) Magnification of a root end with methylene blue added for differentiation

\section{SUMMARY}

The use of magnification, beyond the naked eye, in endodontic treatment has enabled the endodontists to enhance their ability to better identify and treat etiology of endodontic origin. Advance visualization in endodontics has also significantly increased the dentist's ability to identify fracture lines, locate canal orifices and determine anatomic variations in teeth and supporting structures. With the use of loupes, microscopes, rod-lens endoscopes and orasopes elevating the standard of care in the field of endodontics, it is paramount that today's practicing dentist integrates advanced visualization instrumentation into their endodontic treatment.

\section{REFERENCES}

1. Silber S. Microsurgery. Baltimore: William and Wilkins Co; 1979. p. 1.

2. Kagan J, Gehly JC, Wilson HR. The effect of vibration on vision during microsurgery. Microsurgery 1983;4:209-14.

3. Shanelec DA. Optical principles of loupes. J Calif Dent Assoc 1992;20:25-32.

4. Kanca J, Jordan PG. Magnification systems in clinical dentistry. J Can Dent Assoc 1995;61:85

5. Millar BJ. Focus on loupes. Br Dent J 1998;185:504-8.

6. Caplan SA. Magnification in dentistry. J Esthet Dent 1990;2:17-21.

7. Baumann RR. How may the dentist benefit from the operating microscope? Quintessence Int 1977;5:17-8.

8. Selden HS. The role of the dental operating microscope in endodontics. Pa Dent J (Harrisb) 1986;53:36-7.

9. Selden HS. The role of a dental operating microscope in improved nonsurgical treatment of "calcified" canals. Oral Surg Oral Med Oral Pathol 1989;68:93-8.

10. Carr GB. Microscopes in endodontics. J Calif Dent Assoc 1992;20:55-61.

11. Mines P, Loushine RJ, West LA, Liewehr FR, Zadinsky JR. Use of the microscope in endodontics: A report based on a questionnaire. J Endod 1999;25:755-8.

12. Rubinstein R. The anatomy of the surgical operating microscope and operating positions. Dent Clin North Am 1997;41:391-413.

13. Mounce R. Surgical operating microscopes in endodontics: The quantum leap. Dent Today 1993;12:88-91.

14. Nunley JA. Microscopes and microinstruments. Hand Clin 1985;1:197-204.

15. Saunders WP, Saunders EM. Conventional endodontics and the operating microscope. Dent Clin North Am 1997;41:415-28.

16. de Carvalho MC, Zuolo ML. Orifice locating with a microscope. J Endod 2000;26:532-4.

17. Görduysus MO, Görduysus M, Friedman S. Operating microscope improves negotiation of second mesiobuccal canals in maxillary molars. J Endod 2001;27:683-6.

18. Buhrley LJ, Barrows MJ, BeGole EA, Wenckus CS. Effect of magnification on locating the MB2 canal in maxillary molars. J Endod 2002;28:324-7.

19. Kim S, Baek S. The microscope and endodontics. Dent Clin North Am 2004;48:11-8.

20. Rubinstein R. Endodontic microsurgery and the surgical operating microscope. Compend Contin Educ Dent 1997;18:659-72.

21. Detsch SG, Cunningham WT, Langloss JM. Endoscopy as an aid to endodontic diagnosis. J Endod 1979;5:60-2.

22. Held SA, Kao YH, Wells DW. Endoscope - An endodontic application. J Endod 1996;22:327-9. 
23. Shulman BB, Leung A. Endoscopic surgery: An alternative technique. Dent Today 1996;15:42, 44-5.

24. Bahcall J, Barss J. Orascopic visualization technique for conventional and surgical endodontics. Int Endod J 2003;36:441-7.

25. von Arx T, Montagne D, Zwinggi C, Lussi A. Diagnostic accuracy of endoscopy in periradicular surgery-a comparison with scanning electron microscopy. Int Endod J 2003;36:691-9.

26. Taschieri S, Del Fabbro M, Testori T, Francetti L, Weinstein R. Endodontic surgery using 2 different magnification devices: Preliminary results of a randomized controlled study. J Oral Maxillofac Surg 2006;64:235-42.

27. Bahcall JK, DiFiore PM, Poulakidas TK. An endoscopic technique for endodontic surgery. J Endod 1999;25:132-5.

28. Bahcall JK, Barss JT. Fiberoptic endoscope usage for intracanal visualization. J Endod 2001;27:128-9.

29. Bahcall JK, Barss JT. Orascopy: A vision for the new millennium, Part 2. Dent Today 1999;18:82-5.

30. Cambruzzi JV, Marshall FJ, Pappin JB. Methylene blue dye: An aid to endodontic surgery. J Endod 1985;11:311-4.

How to cite this article: Bahcall JK. Visualization in endodontics. Eur J Gen Dent 2013;2:96-101.

Source of Support: Nil, Conflict of Interest: None declared.

Announcement

\section{iPhone App}

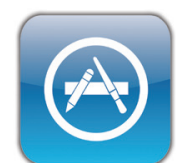

Download

iPhone, iPad application
A free application to browse and search the journal's content is now available for iPhone/iPad. The application provides "Table of Contents" of the latest issues, which are stored on the device for future offline browsing. Internet connection is required to access the back issues and search facility. The application is Compatible with iPhone, iPod touch, and iPad and Requires iOS 3.1 or later. The application can be downloaded from http://itunes.apple.com/us/app/medknow-journals/ id 458064375 ? $\mathrm{s}=1 \mathrm{gmt}=8$. For suggestions and comments do write back to us. 